\title{
COMUNICAÇÃO
}

\section{POTENCIAL ALELOPÁTICO DE Cyperus rotundus L. SOBRE ESPÉCIES CULTIVADAS}

\author{
Allelopathic potential of Cyperus rotundus L. upon cultivated species
}

\author{
Heloísa Monteiro de Andrade ${ }^{1}$, Alexandre Horácio Couto Bittencourt ${ }^{2}$, Silvane Vestena ${ }^{3}$
}

\begin{abstract}
RESUMO
Metabótitos secundários produzidos em algumas plantas podem provocar alterações no desenvolvimento de outras plantas ou até mesmo de outros organismos. Neste trabalho, objetivou-se identificar possíveis efeitos alelopáticos de extratos aquosos de folhas de Cyperus rotundus na germinação e no crescimento de plântulas de Brassica campestris, Brassica oleracea var. botrytis, Brassica oleracea var. capitata, Brassica oleracea var. italica, Brassica rapa, Lactuca sativa cv. Grand rapids, Lycopersicum esculentum e Raphanus sativus. Foram utilizadas sete concentrações do extrato aquoso (0, 10, 30, 50, 70, 90 e $100 \%)$. Os tratamentos foram arranjados em delineamento inteiramente casualizado, com cinco repetições de dez sementes das espécies cultivadas, constituindo a unidade amostral. Os extratos aquosos de C. rotundus evidenciaram potencialidades alelopáticas na germinação das sementes e no crescimento das duas partes vegetais (raiz e parte aérea), de todas as espécies testadas, exceto na germinação de sementes de tomate e de alface, sendo que a redução aumentou com o aumento das concentrações dos extratos aquosos utilizados. A estrutura vegetal mais afetada em presença dos extratos aquosos foi o sistema radicular das plântulas.
\end{abstract}

Termos para indexação: Alelopatia, Germinação de sementes, Crescimento.

\begin{abstract}
Secondary metabolites produced in some plant species may promote changes in the development of other plants or even in other organisms. The aim of this work was to identify the possible allelopathic effects of aqueous extracts of Cyperus rotundus leaves on germination and growth of Brassica campestris, Brassica oleracea var. botrytis, Brassica oleracea var. capitata, Brassica oleracea var. italica, Brassica rapa, Lactuca sativa cv. Grand rapids, Lycopersicum esculentum and Raphanus sativus seedlings. Seven aqueous extract concentrations were used $(0,10,30,50,70,90$, and $100 \%)$. The treatments were arranged in a completely randomized desing, with five replications of ten seeds of each cultivated species constituting the sample unity. The aqueous extracts of $C$. rotundus revealed allelopathic potentialities on germination of seeds and growth of two vegetable parts (root and aerial part) of all tested species, except on germination of $L$. sativa and L. esculentum seeds, being that the reduction increased with the increase of the aqueous concentration extracts which were used. The seedlings roots were the most affected structure in the presence of aqueous extracts.
\end{abstract}

Index terms: Allelopathy, seed germination, growth.

(Recebido em 16 de maio de 2007 e aprovado em 29 de abril de 2008)

Os aleloquímicos, biomoléculas responsáveis pelos efeitos alelopáticos, são produtos naturais que podem ser metabólitos diretos, subprodutos de outros processos metabólicos ou produtos da decomposição de compostos ou biomassa. São freqüentemente nocivos para a planta que produz, se não forem armazenados numa forma não tóxica ou liberados antes de se acumularem internamente até atingirem níveis tóxicos (GLIESSMAN, 2000).
Os efeitos alelopáticos são mediados por substâncias que pertencem a diferentes categorias de compostos secundários (FERREIRA \& ÁQUILA, 2000). Os produtos químicos mais comuns causando efeitos alelopáticos pertencem aos grupos dos ácidos fenólicos, cumarinas, terpenóides, alcalóides, glicosídeos cianogênicos, derivados do ácido benzóico, etileno, saponinas, taninos, quinonas complexas e flavonóides

\footnotetext{
${ }^{1}$ Bióloga, Mestranda em Biologia Celular e Estrututral - Departamento de Biologia Geral - Universidade Federal de Viçosa/UFV - Avenida PH Rolfs, s/n 36570-000 - Viçosa, MG - heloisa_mont@yahoo.com.br

Biólogo, Doutorando em Anatomia Vegetal - Faculdade de Minas/FAMINAS - Avenida Cristiano Ferreira Varella, 655 - Universitário - $36880-000$ Muriaé, MG - ahcouto@faminas.edu.br

${ }^{3}$ Bióloga, Doutora em Fisiologia Vegetal, Professora - Faculdade de Minas/FAMINAS - Avenida Cristiano Ferreira Varella, 655 - Universitário - 36880 -000 Muriaé, MG - svestena@yahoo.com.br
} 
(RODRIGUES \& LOPES, 2001; SOUZA \& FURTADO, 2002; TOKURA \& NÓBREGA, 2006).

De acordo com Rizvi \& Rizvi (1992), os aleloquímicos podem afetar: estruturas citológicas e ultraestruturais; hormônios, tanto alterando suas concentrações quanto o balanço hormonal; membranas e sua permeabilidade; absorção de minerais; movimentos de estômatos; síntese de proteínas; atividade enzimática; relações hídricas e condução; material genético, induzindo alterações no DNA e RNA. Adicionalmente, os aleloquímicos podem causar alterações nas propriedades e características nutricionais do solo, atividades de microrganismos, de nematóides e de insetos.

Segundo Gatti et al. ( 2004), Gliessman (2000) e Singh et al. (2005), os aleloquímicos podem ser liberados pelas plantas lavados das folhas verdes, lixiviados de folhas secas, volatilizados das folhas, exsudados das raízes, ou liberados durante a decomposição de restos de plantas. Mesmo flores, frutos e sementes podem ser fonte de toxinas alelopáticas. Também existem casos em que os produtos não são tóxicos até terem sido alterados no próprio ambiente, seja por degradação química normal ou pela ação de microrganismos.

Muitos estudos estão sendo realizados na tentativa de diminuir o uso de herbicidas sintéticos por meio da alelopatia como o manejo e o controle das plantas invasoras, por meio da rotação de culturas, sistemas adequados de semeadura entre espécies e entressafras, além de sistemas agro-ecológicos (KATO-NOGUCHI, 2003; KHAN et al., 2002; WU et al., 2000).

O cultivo de hortaliças possui algumas exigências técnicas e econômicas que limitam de forma considerável seu manejo, dentre os quais destaca-se o controle de plantas daninhas, tendo em vista que não é permitido o uso de herbicidas. Entre as plantas daninhas, destaca-se a tiririca (Cyperus rotundus L.), considerada a mais importante planta invasora do mundo, apresenta uma alta agressividade e abrangência geográfica, sendo encontrada em todos os países de clima tropical (KISSMANN, 1991). Apesar desta atividade prejudicial, a espécie produz o composto isocurcumenol, que pode ser extraído dos rizomas, tendo sido listados com atividades ansiolítica, remineralizante e com ação protetora contra úlcera gástrica (ARANTES et al., 2005). Na agricultura, o controle de tiririca somente é possível por meio de capinas manuais. Ainda, mesmo com o constante aumento nas investigações do potencial alelopático dessa espécie, o conhecimento desse mecanismo ainda é considerado escasso. Assim, é importante a realização de trabalhos para se conhecer os mecanismos de ação, produção, decomposição de compostos alelopáticos, como também, o ciclo desses compostos nas plantas.

Sendo assim, este trabalho foi realizado com o objetivo de verificar o potencial alelopático de folhas secas de tiririca (Cyperus rotundus L.) sobre a germinação de sementes e o desenvolvimento de plântulas de mostarda (Brassica campestris L.), brócolis (Brassica oleracea L. var. italica), couve-flor (Brassica oleracea L. var. botrytis), repolho (Brassica oleracea L. var. capitata), nabo (Brassica rapa $\mathrm{L}$.), alface (Lactuca sativa L. cv.. Grand rapids), tomate (Lycopersicum esculentum Miller) e rabanete (Raphanus sativus L.).

Os bioensaios foram conduzidos no Laboratório de Ciências Biológicas da Faculdade de Filosofia, Ciências e Letras Santa Marcelina - FAFISM, Muriaé, MG. Folhas de tiririca foram coletadas no município de Muriaé, MG, sendo secas em estufa a $70^{\circ} \mathrm{C}$ até obtenção de massa seca estável (JACOBI \& FERREIRA, 1991).

Para a realização dos bioensaios de germinação foram utilizados sementes de tomate, alface, repolho, nabo, brócolis, couve-flor, mostarda e rabanete, sendo que as sementes foram obtidas no comércio local. Foram efetuados testes preliminares em laboratório para verificação da viabilidade e do vigor da germinação das sementes.

Para a obtenção do extrato aquoso de tiririca foi utilizado folhas previamente secas na concentração de $1 \mathrm{~g}$ $10 \mathrm{~mL}^{-1}(\mathrm{p} / \mathrm{v}),(1 \mathrm{~g}$ de matéria vegetal para $10 \mathrm{~mL}$ de água destilada) sendo trituradas em um liquidificador. A mistura foi deixada em repouso por 48 horas na geladeira $\left(5^{\circ} \pm 1^{\circ} \mathrm{C}\right)$, sendo, após, filtrada em funil-de-büchner, por duas vezes, usando-se papel filtro qualitativo, segundo a metodologia proposta por Jacobi \& Ferreira (1991). O extrato concentrado foi diluído em seis concentrações diferentes $(10,30,50,70,90,100 \%)$ e utilizado água destilada como tratamento controle.

Para os testes de germinação foram utilizadas placasde-petri esterilizadas de $9 \mathrm{~cm}$ de diâmetro, forradas com dois discos de papel-filtro, sendo umedecidas com $10 \mathrm{~mL}$ de água destilada (controle) ou do extrato aquoso. Os bioensaios foram constituídos pelas sete concentrações, com cinco repetições cada, com dez sementes das espécies cultivadas para cada placa-de-petri, constituíndo a unidade amostral. Foram consideradas germinadas as sementes que apresentaram $2 \mathrm{~mm}$ de protusão radicular (BRASIL, 1992). O experimento foi mantido por um período de 10 dias, sendo que diariamente foi verificado o número de sementes germinadas. Para os dados do crescimento das plântulas, foi coletado, no final dos 10 dias de experimento, o comprimento em centímetros da raiz e da parte aérea. 
O experimento foi montado em um delineamento inteiramente casualizado. Os resultados obtidos foram submetidos à análise de variância (ANOVA) e as médias, discriminadas pelo teste Tukey a $5 \%$ de probabilidade (BEIGUELMAN, 2002).

Verificou-se que os extratos aquosos de folhas secas de tiririca reduziram o percentual de germinação de brócolis, repolho, nabo, rabanete e couve-flor e, não reduziram o percentual de germinação de sementes de tomate e de alface, independente das concentrações utilizadas (Tabela 1). O percentual de germinação de sementes de repolho foi reduzida apenas pelas últimas concentrações (90 e 100\%) do extrato aquoso utilizado, quando comparado ao tratamento controle, reduções estas de 57,1 e $57,1 \%$, respectivamente.

Adicionalmente, os extratos aquosos de folhas de tiririca reduziram o percentual de germinação de sementes de nabo, brócolis, couve-flor e de rabanete a partir da concentração de $70 \%$, quando comparado ao tratamento controle. Reduções estas de 28, 32 e $64 \%$, respectivamente para sementes de nabo; $54,5,54,5$ e $77,2 \%$, respectivamente para sementes de brócolis; 60,60 e $85 \%$, respectivamente para sementes de couve-flor e, 20,8, 37,5 e 41,6\%, respectivamente para sementes de rabanete. Sementes de alface e de tomate, não sofreram reduções no percentual de germinação em presença dos extratos aquosos utilizados, quando comparado ao tratamento controle. $\mathrm{O}$ percentual de germinação de sementes de mostarda, sofreu redução pelos extratos aquosos a partir da concentração de 50\%. Independente das espécies testadas, exceto para o tomate, foi verificado um aumento na redução do percentual de germinação com o aumento das concentrações utilizadas.
Ainda, foi verificado que os extratos aquosos nas concentrações de 10,30 e $50 \%$ não reduziram ou estimularam o percentual de germinação das espécies testadas, quando comparado ao tratamento controle, exceto para mostarda. Para a maioria das espécies este parâmetro foi reduzido a partir da concentração de $70 \%$, quando comparado ao tratamento controle (Tabela 1).

Nos estudos alelopáticos, a germinabilidade é um índice muito usado, embora não demonstre outros aspectos do processo de germinação, como atrasos, já que envolve apenas resultados finais, ignorando períodos de germinação inativa no decorrer do bioensaio (CHIAPUSO et al., 1997). Muitas vezes, o que se observa são efeitos significativos de extratos sobre o tempo médio e entropia de germinação e nenhuma diferença na germinabilidade, em relação ao controle (FERREIRA \& ÁQUILA, 2000), sendo que o mesmo foi verificado nos bioensaios realizados com as sementes de alface e de tomate.

As alterações no padrão de germinação podem resultar de diversos efeitos causados em nível primário. Entre elas, Ferreira \& Áquila (2000) destacam alterações na permeabilidade de membranas, na transcrição e tradução do DNA, no funcionamento de mensageiros secundários, na respiração, em razão do seqüestro do oxigênio, na conformação de enzimas e receptores, ou ainda pela combinação destes fatores.

Periotto et al. (2004), usando extratos aquosos de Andira humilis Mart. ex Benth. observaram que alface e rabanete mostram-se sensíveis. Os extratos aquosos inibiram o percentual de germinação apenas na última concentração do extrato aquoso, ou seja, na concentração de $16 \%(\mathrm{p} / \mathrm{v})$. França et al. (2008) verificaram que extratos aquosos, metanólicos e exanólicos de nim (Azadirachta

Tabela 1 - Efeito alelopático de extratos aquosos de folhas secas de tiririca (Cyperus rotundus) sobre a germinação de sementes $(\%)$ de espécies cultivadas.

\begin{tabular}{|c|c|c|c|c|c|c|c|c|}
\hline \multicolumn{9}{|c|}{ Concentração do extrato (\%) } \\
\hline Espécie vegetal & 0 & 10 & 30 & 50 & 70 & 90 & 100 & $\mathrm{CV}(\%)$ \\
\hline Brassica campestris & $100 \pm 0,00 \mathrm{a}$ & $100 \pm 0,00 \mathrm{a}$ & $96 \pm 0,45 \mathrm{a}$ & $64 \pm 1,48 b$ & $20 \pm 0,71 \mathrm{c}$ & $20 \pm 1,00 \mathrm{c}$ & $8 \pm 0,55 \mathrm{c}$ & 11,58 \\
\hline Brassica oleracea var. botrytis & $80 \pm 1,22 \mathrm{a}$ & $76 \pm 1,10 \mathrm{a}$ & $64 \pm 0,45 \mathrm{ab}$ & $60 \pm 0,71 \mathrm{ab}$ & $32 \pm 1,14 \mathrm{c}$ & $32 \pm 0,89 \mathrm{c}$ & $12 \pm 0,89 \mathrm{~d}$ & 18,57 \\
\hline Brassica oleracea var. capitata & $84 \pm 0,45 \mathrm{a}$ & $84 \pm 0,84 \mathrm{a}$ & $72 \pm 0,89 \mathrm{ab}$ & $64 \pm 0,84 \mathrm{ab}$ & $64 \pm 0,84 \mathrm{ab}$ & $36 \pm 1,64 b$ & $36 \pm 1,30 \mathrm{~b}$ & 16,85 \\
\hline Brassica oleracea var. italica & $88 \pm 0,55 \mathrm{a}$ & $88 \pm 0,55 \mathrm{a}$ & $88 \pm 0,55 \mathrm{a}$ & $64 \pm 1,79 \mathrm{ab}$ & $40 \pm 0,00 \mathrm{c}$ & $40 \pm 1,22 \mathrm{c}$ & $20 \pm 1,00 \mathrm{~d}$ & 19,63 \\
\hline Brassica rapa & $100 \pm 0,00 \mathrm{a}$ & $100 \pm 0,00 \mathrm{a}$ & $92 \pm 0,55 \mathrm{a}$ & $88 \pm 0,55 \mathrm{ab}$ & $72 \pm 0,89 b$ & $68 \pm 0,55 b$ & $36 \pm 1,48 b$ & 13,08 \\
\hline Lactuca sativa var. grand rapids & $100 \pm 0,00 \mathrm{a}$ & $96 \pm 0,45 \mathrm{a}$ & $92 \pm 0,89 \mathrm{a}$ & $92 \pm 1,14 \mathrm{a}$ & $92 \pm 0,55 \mathrm{a}$ & $88 \pm 1,34 \mathrm{a}$ & $76 \pm 0,84 \mathrm{a}$ & 17,96 \\
\hline Lycopersicum esculentum & $92 \pm 0,00 \mathrm{a}$ & $92 \pm 0,00 \mathrm{a}$ & $92 \pm 0,55 \mathrm{a}$ & $92 \pm 0,55 \mathrm{a}$ & $92 \pm 0,89 \mathrm{a}$ & $92 \pm 0,55 \mathrm{a}$ & $84 \pm 0,84 \mathrm{a}$ & 10,32 \\
\hline Raphanus sativus & $96 \pm 0,45 \mathrm{a}$ & $92 \pm 0,89 \mathrm{a}$ & $92 \pm 0,55 \mathrm{a}$ & $92 \pm 0,55 \mathrm{a}$ & $76 \pm 0,84 b$ & $60 \pm 1,00 \mathrm{~b}$ & $56 \pm 0,84 \mathrm{bc}$ & 15,35 \\
\hline
\end{tabular}

As médias e desvio padrão seguidas pelas mesmas letras nas linhas não diferem estatisticamente pelo teste de Tukey a $5 \%$ de probabilidade. 
indica A. Juss.) reduzem o percentual de germinação sobre plântulas de alface. Também, Gatti et al. (2004) trabalhando com extratos aquosos de folhas de Aristolochia esperanzae Kuntze verificaram que esta espécie reduziu o percentual de germinação de alface e de rabanete em todas as concentrações dos extratos utilizados, ou seja, de 50 e $100 \%$, quando comparado ao tratamento controle. Entretanto Ferreira et al. (2007) observaram que o extrato etanólico de Pinus elliottii não apresentou efeito alelopático sobre o alface, porém o extrato etanólico de Eucalyptus citriodora reduziu de forma significativa a velocidade de germinação.

Adicionalmente, os extratos aquosos de folhas secas de tiririca reduziram o crescimento da parte aérea e do sistema radicular de todas as espécies testadas (mostarda, couve-flor, repolho, brócolis, nabo, alface, tomate e rabanete) (Tabelas 2 e 3 ).

O crescimento inicial da parte aérea de plântulas de tomate foi reduzido apenas na concentração de $100 \%$ do extrato aquoso, quando comparado ao tratamento controle. Redução esta de 41,1\% (Tabela 2). Para o sistema radicular desta espécie, o crescimento foi reduzido a partir da concentração de $30 \%$ do extrato aquoso, quando comparado ao tratamento controle, sendo observada uma crescente redução no crescimento tanto da parte aérea como do sistema radicular com o aumento das concentrações dos extratos aquosos utilizados (Tabela 3).

Para alface, repolho, brócolis e couve-flor, foi verificado que os extratos aquosos de folhas de tiririca inibiram o crescimento inicial da parte aérea e do sistema radicular nas espécies testadas (Tabelas 2 e 3). Para as plântulas de alface, os extratos aquosos de tiririca reduziram o crescimento do sistema radicular a partir da concentração de $10 \%$, quando comparado ao tratamento controle, sendo que a redução no crescimento aumentou com o aumento das concentrações dos extratos aquosos utilizados (Tabela 3); enquanto que, para a parte aérea desta espécie, o crescimento foi reduzido apenas pelas concentrações mais altas (90 e 100\%). Reduções estas de 42,2 e 64,4\%, respectivamente (Tabela 2). Ainda, o crescimento inicial da parte aérea e do sistema radicular das plântulas de repolho foi reduzido a partir da concentração de 50 e $30 \%$ do extrato aquoso utilizado, respectivamente, quando comparado ao tratamento controle (Tabelas 2 e 3); enquanto que, o crescimento inicial tanto da parte aérea como do sistema radicular das plântulas

Tabela 2 - Efeito alelopático de extratos aquosos de folhas secas de tiririca (Cyperus rotundus) sobre o crescimento da parte aérea $(\mathrm{cm})$ de espécies cultivadas.

\begin{tabular}{|c|c|c|c|c|c|c|c|c|}
\hline \multicolumn{9}{|c|}{ Concentração do extrato (\%) } \\
\hline Espécie vegetal & 0 & 10 & 30 & 50 & 70 & 90 & 100 & $\mathrm{CV}(\%)$ \\
\hline Brassica campestris & $4,7 \pm 0,60 \mathrm{a}$ & $4,6 \pm 0,40 \mathrm{a}$ & $4,6 \pm 0,67 \mathrm{a}$ & $3,0 \pm 0,25 a b$ & $0,6 \pm 0,54 \mathrm{c}$ & $0,5 \pm 0,63 \mathrm{c}$ & $0,0 \pm 0,00 \mathrm{c}$ & 16,59 \\
\hline Brassica oleracea var. botrytis & $4,2 \pm 0,48 \mathrm{a}$ & $4,2 \pm 1,42 \mathrm{a}$ & $3,1 \pm 0,61 \mathrm{ab}$ & $2,4 \pm 0,84 \mathrm{~b}$ & $1,1 \pm 0,13 \mathrm{c}$ & $1,0 \pm 0,61 \mathrm{c}$ & $0,2 \pm 0,28 \mathrm{~d}$ & 20,03 \\
\hline Brassica oleracea var. capitata & $4,2 \pm 0,30 \mathrm{a}$ & $3,5 \pm 0,76 \mathrm{a}$ & $3,5 \pm 0,36 \mathrm{a}$ & $2,5 \pm 0,27 \mathrm{~b}$ & $2,2 \pm 0,61 b$ & $0,5 \pm 0,22 \mathrm{c}$ & $0,5 \pm 0,07 \mathrm{c}$ & 17,98 \\
\hline Brassica oleracea var. italica & $3,6 \pm 0,86 a$ & $3,6 \pm 0,96 \mathrm{a}$ & $3,5 \pm 0,45 \mathrm{a}$ & $3,0 \pm 1,36$ a & $1,3 \pm 0,63 b$ & $1,3 \pm 0,54 \mathrm{~b}$ & $0,9 \pm 0,63 \mathrm{~b}$ & 19,28 \\
\hline Brassica rapa & $3,0 \pm 0,32 \mathrm{a}$ & $2,9 \pm 0,26 \mathrm{a}$ & $2,3 \pm 0,43 \mathrm{a}$ & $2,0 \pm 0,96 \mathrm{ab}$ & $0,0 \pm 0,00 \mathrm{c}$ & $0,0 \pm 0,00 \mathrm{c}$ & $0,0 \pm 0,00 \mathrm{c}$ & 19,01 \\
\hline Lactuca sativa var. grand rapids & $4,5 \pm 0,16 \mathrm{a}$ & $4,5 \pm 0,24 \mathrm{a}$ & $4,4 \pm 0,19 \mathrm{a}$ & $4,0 \pm 0,73 \mathrm{a}$ & $4,0 \pm 0,40 \mathrm{a}$ & $2,6 \pm 0,47 \mathrm{~b}$ & $1,6 \pm 0,43 \mathrm{c}$ & 11,34 \\
\hline Lycopersicum esculentum & $9,0 \pm 0,22 \mathrm{a}$ & $9,0 \pm 0,44 \mathrm{a}$ & $8,4 \pm 0,29 a$ & $8,0 \pm 0,75 \mathrm{a}$ & $7,4 \pm 0,27 \mathrm{ab}$ & $7,2 \pm 0,60 \mathrm{ab}$ & $5,3 \pm 0,43 \mathrm{c}$ & 14,83 \\
\hline Raphanus sativus & $4,6 \pm 0,30 \mathrm{a}$ & $4,1 \pm 0,45 \mathrm{a}$ & $1,9 \pm 0,40 \mathrm{~b}$ & $0,9 \pm 0,13 \mathrm{c}$ & $0,0 \pm 0,00 \mathrm{~d}$ & $0,0 \pm 0,00 \mathrm{~d}$ & $0,0 \pm 0,00 \mathrm{~d}$ & 18,48 \\
\hline
\end{tabular}

As médias e desvio padrão seguidas pelas mesmas letras nas linhas não diferem estatisticamente pelo teste de Tukey a $5 \%$ de probabilidade.

Tabela 3 - Efeito alelopático de extratos aquosos de folhas secas de tiririca (Cyperus rotundus) sobre o crescimento do sistema radicular $(\mathrm{cm})$ de especies cultivadas.

\begin{tabular}{|c|c|c|c|c|c|c|c|c|}
\hline \multicolumn{9}{|c|}{ Concentração do extrato (\%) } \\
\hline Espécie vegetal & 0 & 10 & 30 & 50 & 70 & 90 & 100 & $\mathrm{CV}(\%)$ \\
\hline Brassica campestris & $4,3 \pm 0,13 \mathrm{a}$ & $4,2 \pm 1,63 \mathrm{a}$ & $4,3 \pm 0,29 \mathrm{a}$ & $2,4 \pm 0,38 b$ & $0,4 \pm 0,26 \mathrm{c}$ & $0,4 \pm 0,35 \mathrm{c}$ & $0,0 \pm 0,00 \mathrm{c}$ & 19,61 \\
\hline Brassica oleracea var. botrytis & $4,8 \pm 2,06 \mathrm{a}$ & $4,3 \pm 1,31 \mathrm{a}$ & $3,7 \pm 1,22 \mathrm{a}$ & $1,3 \pm 0,46 b$ & $0,5 \pm 0,28 \mathrm{c}$ & $0,4 \pm 0,34 \mathrm{c}$ & $0,1 \pm 0,12 \mathrm{c}$ & 15,79 \\
\hline Brassica oleracea var. capitata & $5,2 \pm 0,54 \mathrm{a}$ & $4,6 \pm 0,48 \mathrm{a}$ & $3,5 \pm 0,80 \mathrm{~b}$ & $2,2 \pm 0,19 \mathrm{c}$ & $1,8 \pm 0,34 \mathrm{c}$ & $0,3 \pm 0,15 \mathrm{~d}$ & $0,3 \pm 0,09 \mathrm{~d}$ & 19,52 \\
\hline Brassica oleracea var. italica & $4,2 \pm 1,26 \mathrm{a}$ & $4,1 \pm 0,87 \mathrm{a}$ & $3,7 \pm 0,64 \mathrm{a}$ & $1,6 \pm 0,77 \mathrm{~b}$ & $0,4 \pm 0,25 \mathrm{c}$ & $0,4 \pm 0,27 \mathrm{c}$ & $0,1 \pm 0,05 \mathrm{c}$ & 16,57 \\
\hline Brassica rapa & $3,9 \pm 0,11 \mathrm{a}$ & $3,8 \pm 0,17 \mathrm{a}$ & $1,8 \pm 0,16 \mathrm{~b}$ & $0,9 \pm 0,27 \mathrm{c}$ & $0,0 \pm 0,00 \mathrm{~d}$ & $0,0 \pm 0,00 \mathrm{~d}$ & $0,0 \pm 0,00 \mathrm{~d}$ & 11,97 \\
\hline Lactuca sativa var. grand rapids & $4,6 \pm 0,22 \mathrm{a}$ & $3,3 \pm 0,50 b$ & $2,8 \pm 0,30 \mathrm{~b}$ & $2,0 \pm 0,18 \mathrm{c}$ & $1,4 \pm 0,15 \mathrm{~d}$ & $0,7 \pm 0,16 \mathrm{e}$ & $0,5 \pm 0,09 \mathrm{e}$ & 12,01 \\
\hline Lycopersicum esculentum & $8,9 \pm 0,58 \mathrm{a}$ & $6,5 \pm 0,37 \mathrm{ab}$ & $5,5 \pm 0,29 b$ & $5,3 \pm 0,33 b$ & $4,4 \pm 0,36 \mathrm{bc}$ & $4,2 \pm 0,24 \mathrm{bc}$ & $3,1 \pm 0,18 \mathrm{c}$ & 17,72 \\
\hline Raphanus sativus & $6,4 \pm 0,71 \mathrm{a}$ & $5,8 \pm 0,75 \mathrm{a}$ & $2,2 \pm 0,16 \mathrm{~b}$ & $0,5 \pm 0,09 \mathrm{c}$ & $0,0 \pm 0,00 \mathrm{~d}$ & $0,0 \pm 0,00 \mathrm{~d}$ & $0,0 \pm 0,00 \mathrm{~d}$ & 16,38 \\
\hline
\end{tabular}

As médias e desvio padrão seguidas pelas mesmas letras nas linhas não diferem estatisticamente pelo teste de Tukey a 5\% de probabilidade. 
de couve-flor foi reduzido a partir da concentração de $50 \%$ (Tabelas 2 e 3). O crescimento inicial da parte aérea das plântulas de brócolis foi reduzido a partir da concentração de $70 \%$ e, o crescimento do sistema radicular foi reduzido a partir da concentração de $50 \%$ (Tabelas 2 e 3).

Os extratos aquosos de folhas de tiririca, também apresentaram efeitos inibitórios no crescimento das plântulas de nabo, rabanete e mostarda (Tabelas 2 e 3). Para o nabo a redução do crescimento inicial da parte aérea ocorreu a partir da concentração de $70 \%$ e, do sistema radicular, a partir da concentração de 30\%. Para as plântulas de rabanete os extratos aquosos de folhas de tiririca reduziram o crescimento da parte aérea e do sistema radicular a partir da concentração de $30 \%$ do extrato aquoso. Além disso, observou-se que a partir da concentração de $70 \%$ o crescimento tanto da parte aérea como do sistema radicular de ambas as espécies foi nulo. Para as plântulas de mostarda, o crescimento inicial da parte aérea foi reduzido a partir da concentração de $70 \%$. Reduções estas de 87,2, 89,3 e 100\%, respectivamente (Tabela 2) e, para o crescimento do sistema radicular desta espécie, foi verificada redução a partir da concentração de $50 \%$ dos extratos aquosos utilizados (Tabela 3). Além disso, para as duas partes vegetais desta espécie, quando foi utilizado o extrato na concentração de $100 \%$, foi verificado que o extrato inibiu completamente o crescimento inicial das plântulas (Tabelas 2 e 3). Independente das espécies testadas, o crescimento inicial tanto da parte aérea como do sistema radicular foi reduzido com o aumento das concentrações dos extratos aquosos utilizados.

Ainda, para o crescimento inicial do sistema radicular, exceto em plântulas de alface, na concentração de $10 \%$ do extrato aquoso não foi verificada redução ou estímulo no crescimento inicial das plântulas das espécies testadas, quando comparado ao tratamento controle. Para a maioria das espécies o crescimento inicial foi reduzido a partir das concentrações de 30 ou $50 \%$, quando comparado ao tratamento controle (Tabela 3 ).

Como constatado no presente trabalho, os efeitos alelopáticos podem ser observados tanto sobre a germinação quanto sobre o crescimento da plântula. $\mathrm{O}$ efeito é mais drástico sobre o crescimento do que sobre a germinação (FERREIRA \& ÁQUILA, 2000; IGANCI et al., 2006). Resultados similares já foram encontrados com Jacobi \& Ferreira (1991) quando observaram que extratos aquosos de folhas de maricá (Mimosa bimucronata (DC) OK.) inibiram a germinação e o crescimento da radícula de algumas espécies hortícolas como Lactuca sativa L., Oryza sativa L., Daucus carota L., Cichorium endivia L.,
Brassica pekinensis (Lour.) Skeels, Cucumis sativus L., Brassica oleracea L. e Lycopersicum esculentum Miller e, que este efeito dependia da época do ano em que as folhas fossem coletadas e da espécie alvo. É possível que compostos fenólicos como isocurcumenol presentes em Cyperus rotundus L., possam exibir propriedades biológicas interessantes, podendo ser estes componentes majoritários da espécie (ARANTES et al., 2005) e, sendo assim, os responsáveis pelos efeitos fitotóxicos na germinação das sementes e no crescimento inicial das plântulas das espécies testadas. Estes resultados são respaldados por Melo et al. (2001), ao descrever que extratos de tubérculos de tiririca inibiram a germinação de Lycopersicum esculentum, Sorghum bicolor (L.) Moench, Zea mays L. e Piper regnellii (Miq.) C. DC., e, extratos foliares da espécie inibiram o crescimento de Phaseolus vulgaris L., Gossypium herbaceum L. e Saccharum officinarum $\mathrm{L}$.

Independente das espécies testadas observou-se que a estrutura vegetal que mais sofreu o efeito do extrato de folhas secas de tiririca foi o sistema radicular, pois é a parte vegetal que primeiro mantém contato com o extrato aquoso. Reduções estas que também foram intensificadas com o aumento das concentrações dos extratos utilizados.

Adicionalmente, em relação à influência alelopática no crescimento das plântulas das espécies testadas foram registradas anormalidades, principalmente no sistema radicular, onde as raízes primárias se apresentaram atrofiadas, defeituosas e, em alguns casos, praticamente ausentes. Anormalidades em plântulas de alface e de rabanete também foram observadas por Medeiros \& Luchesi (1993) com o uso de extratos aquosos de ervilhaca (Vicia sativa L.) e por Áquila (2000), com extratos de ervamate (Ilex paraguariensis A. St.-Hil.) e Gatti et al. (2004) com extratos de folhas de Aristolochia esperanzae. A presença de anormalidades em raízes parece ser um bom parâmetro para registro de anormalidade de plântula, pois este órgão é mais sensível à ação alelopática que a parte aérea (PIRES \& OLIVEIRA, 2001).

É comum encontrar nas plantas superiores, compostos com propriedades alelopáticas diversificadas quimicamente, sendo que, a quantidade e a composição destes podem variar com a espécie estudada. Também, deve ser considerado que em condições de solo o efeito dos agentes aleloquímicos pode ser diferente do observado in vitro. Os processos utilizados para demonstrar que determinados extratos têm efeitos alelopáticos não prova mais do que a existência de aleloquímicos no material vegetal, não podendo inferir que em condições a campo elas se manifestem. 
Desta forma, os resultados do presente trabalho indicam a presença de toxidez e, possivelmente, potencial alelopático promovido pelas folhas secas de tiririca. Este efeito se manifestou por meio da redução ou na inibição do percentual de germinação e do crescimento das plântulas das espécies testadas.

Os extratos aquosos de folhas secas de Cyperus rotundus não reduziram o percentual de germinação de sementes de Lycopersicum esculentum e de Lactuca sativa cv. Grand rapids, porém a germinação das sementes de Brassica campestris, Brassica oleracea var. botrytis, Brassica oleracea var. capitata, Brassica oleracea var. italica, Brassica rapa e Raphanus sativus foram afetadas pelos extratos.

Os extratos aquosos de folhas secas de $C$. rotundus reduziram o crescimento das duas partes vegetais de todas as espécies testadas, sendo que na $B$. rapa e $R$. sativus foram as espécies que mais sofreram o efeito dos extratos aquosos de $C$. rotundus.

Os efeitos alopáticos foram observados tanto na germinação quanto no crescimento da plântula, sendo o efeito mais drástico sobre o crescimento inicial do que sobre a germinação.

A variável testada mais afetada pelos extratos foi o comprimento inicial do sistema radicular das plântulas.

\section{REFERÊNCIAS BIBLIOGRÁFICAS}

AQUILA, M. E. A. Efeito alelopático de Ilex paraguariensis A. St.-Hil. na germinação e crescimento inicial de Lactuca sativa L. Iheringia - Série Botânica, Porto Alegre, v. 53, p. 51-66, 2000.

ARANTES, M. C. B.; OLIVEIRA, L. M. G.; FREITAS, M. R. F.; SILVA, L. N. M.; NOGUEIRA, J. C. M.; PAULA, J. R.; BARA, M. T. F. Estudo farmacognóstico do Cyperus rotundus L. Revista Eletrônica de Farmácia, Goiânia, v. 2, n. 2, p. 17-20, 2005.

BEIGUELMAN, B. Curso prático de bioestatística. 5. ed. Ribeirão Preto: Funpec, 2002. 274 p.

BRASIL. Ministério da Agricultura e Reforma Agrária. Regras para análise de sementes. Brasília, DF: SNDA/ DNDV/CLAV, 1992.

CHIAPUSIO, G.; SÁNCHEZ, A. M.; REIGOSA, M. J.; GONZÁLEZ, L.; PELLISSIER, F. Do germination indices adequately reflect allelochemical effects on the germination process? Journal of Chemical Ecology, New York, v. 23, p. 2445-2453, 1997.
FERREIRA, A. G.; ÁQUILA, M. E. A. Alelopatia: uma área emergente da ecofisiologia. Revista Brasileira de Fisiologia Vegetal, Campinas, v. 12, p. 175-204, 2000. Edição especial.

FERREIRA, M. C.; SOUZA, J. R. P. de; FARIA, T. de J. Potenciação alelopática de extratos vegetais na germinação e no crescimento inicial de picão-preto e alface. Ciência e Agrotecnologia, Lavras, v. 31, n. 4, p. 1054-1060, jul./ago., 2007.

FRANÇA, A. C.; SOUZA, I. F. de; SANTOS, C. C. dos; OLIVEIRA, E. Q. de; MARTINOTTO, C. Atividades alelopáticas de nim sobre o crescimento de sorgo, alface e picão-preto. Ciência e Agrotecnologia, Lavras, v.32, n.5, p. 1374-1379, set./out., 2008.

GATTI, A. B.; PEREZ, S. C. J. G. A.; LIMA, M. I. S. Atividade alelopática de extratos aquosos de Aristolochia esperanzae O. Kuntze na germinação e no crescimento de Lactuca sativa L. e Raphanus sativus L. Acta Botanica Brasilica, São Paulo, v. 18, n. 3, p. 459472, 2004

GLIESSMAN, S. R. Agroecologia: processos ecológicos em agricultura sustentável. Porto Alegre: UFRGS, 2000. $653 \mathrm{p}$.

IGANCI, J. R. V.; BOBROWSKI, V. L.; HEIDEN, G.; STEIN, V. C.; ROCHA, B. H. G. Efeito do extrato aquoso de diferentes espécies de boldo sobre a germinação e índice mitótico de Allium cepa L. Arquivos do Instituto Biológico de São Paulo, São Paulo, v. 73, n. 1, p. 79-82, 2006.

JACOBI, U. S.; FERREIRA, A. G. Efeitos alelopáticos de Mimosa bimucronata (DC) OK. sobre espécies cultivadas. Pesquisa Agropecuária Brasileira, Brasília, v. 26, n. 7, p. 935-943, 1991.

KATO-NOGUCHI, H. Assessment of allelopathic potencial of shoot powder of lemon balm. Scientia Horticulturae, Amsterdam, v. 97, p. 419-423, 2003.

KHAN, Z. R.; HASSANALI, A.; OVERHOLT, W.; KHAMIS, T.; HOOPER, A. M.; PICHETT, J. A.; WADHAMS, L. J.; WOODCOCK, C. M. Control of witchweed Striga hermonthica by intercropping with Desmodium spp., and the mechanism defined as allelopathic. Journal of Chemical Ecology, New York, v. 28, n. 9, p. 1871-1885, 2002. 
KISSMANN, K. G. Plantas infestantes e nocivas. São Paulo: BASF-Brasileira, 1991. 608 p.

MEDEIROS, A. R. M.; LUCCHESI, A. A. Efeitos alelopáticos da ervilhaca (Vicia sativa L.) sobre a alface em testes de laboratório. Pesquisa Agropecuária Brasileira, Brasília, v. 28, n. 1, p. 9-14, 1993.

MELO, H. B.; FERREIRA, L. R.; SILVA, A. A.; MIRANDA, G. V.; ROCHA, V. S.; SIVA, C. M. M. Interferência das plantas daninhas na cultura da soja cultivada em dois espaçamentos entre linhas. Planta Daninha, Viçosa, v. 19, n. 2, p. 187-191, 2001.

PERIOTTO, F.; PEREZ, S. C. J. G. A.; LIMA, M. I. S. Efeito alelopático de Andira humilis Mart. ex. Benth na germinação e no crescimento de Lactuca sativa L. e Raphanus sativus L. Acta Botanica Brasilica, São Paulo, v. 18, n. 3, p. 425-430, 2004.

PIRES, N. M.; OLIVEIRA, V. R. Alelopatia. In: OLIVEIRA, R. S.; CONSTANTIN, J. Plantas daninhas e seu manejo. Guaíba: Agropecuária, 2001. cap. 5, p. 145-185.

RIZVI, S. J. H.; RIZVI, V. Exploration of allelochemicals in improving crop productivity. In:
Allelopathy: basic and applied aspects. London: Chapman \& Hall, 1992. p. 443-472.

RODRIGUES, F. C. M.; LOPES, B. M. Potencial alelopático de Mimosa caesalpinaefolia Benth sobre sementes de Tabebuia alba (Cham.) Sandw. Floresta e Ambiente, Seropédica, v. 8, n. 1, p. 130-136, 2001.

SINGH, H. P.; BATISH, D. R.; PANDHER, J. K.; KOHLI, R. K. Phytotoxic effects of Parthenium hysterophorus residues on three Brassica species. Weed Biology and Management, Kyoto, v. 5, p. 105-109, 2005.

SOUZA, I. F.; FURTADO, D. A. S. Caracterização de aleloquimicos do centeio (Secale cereale) e seu potencial alelopático sobre plantas de alface (Lactuca sativa). Ciência e Agrotecnologia, Lavras, v. 26, n. 5, p. 1097-1099, 2002.

TOKURA, L. K.; NÓBREGA, L. H. P. Alelopatia de cultivos de cobertura vegetal sobre plantas infestantes. Acta Scientiarum Agronomy, Maringá, v. 28, n. 3, p. 379-383, 2006.

WU, H.; HAIG, T.; PRATLEY, J.; LEMERLE, D.; AN, M. Distribuition and exudation of allelochemicals in wheat Triticum aestivum. Journal of Chemical Ecology, New York, v. 26, n. 9, p. 2141-2154, 2000. 